\title{
Goosecoid acts cell autonomously in mesenchyme-derived tissues during
} \section{craniofacial development}

\author{
Jaime A. Rivera-Pérez*, Maki Wakamiya and Richard R. Behringerł \\ Department of Molecular Genetics, The University of Texas M. D. Anderson Cancer Center, 1515 Holcombe Boulevard, Houston, \\ TX 77030, USA \\ *Present address: Department of Genetics, 10900 Euclid Ave., Case Western Reserve University, Cleveland, OH 44106, USA \\ ¥Author for correspondence (e-mail: bhr@molgen.mda.uth.tmc.edu) \\ Accepted 8 June; published on WWW 5 August 1999
}

\section{SUMMARY}

Mice homozygous for a targeted deletion of the homeobox gene Goosecoid (Gsc) have multiple craniofacial defects. To understand the mechanisms responsible for these defects, the behavior of $G s c$-null cells was examined in morula aggregation chimeras. In these chimeras, Gsc-null cells were marked with $\beta$-galactosidase $(\beta$-gal) activity using the ROSA26 lacZ allele. In addition, mice with a lacZ gene that had been introduced into the $G s c$ locus were used as a guide to visualize the location of Gsc-expressing cells. In Gscnull $\leftrightarrow$ wild-type chimeras, tissues that would normally not express $G s c$ were composed of both $G s c$-null and wild-type cells that were well mixed, reflecting the overall genotypic composition of the chimeras. However, craniofacial tissues that would normally express Gsc were essentially devoid of $G s c$-null cells. Furthermore, the nasal capsules and mandibles of the chimeras had defects similar to Gsc-null mice that varied in severity depending upon the proportion of $G s c$-null cells. These results combined with the analysis of $G s c$-null mice suggest that Gsc functions cell autonomously in mesenchyme-derived tissues of the head. A developmental analysis of the tympanic ring bone, a bone that is always absent in Gsc-null mice because of defects at the cell condensation stage, showed that Gsc-null cells had the capacity to form the tympanic ring condensation in the presence of wild-type cells. However, analysis of the tympanic ring bones of $\mathbf{1 8 . 5}$ d.p.c. chimeras suggests that $G s c$-null cells were not maintained. The participation of $G s c$-null cells in the tympanic ring condensation of chimeras may be an epigenetic phenomenon that results in a local environment in which more precursor cells are present. Thus, the skeletal defects observed in Gsc-null mice may reflect a regional reduction of precursor cells during embryonic development.

Key words: Goosecoid, Homeobox, Craniofacial development, Mouse chimera

\section{INTRODUCTION}

Most of the morphological and functional differences between vertebrates and other chordates are found in the head (Gans and Northcutt, 1983). The vertebrate head is a complex assemblage of skeletal, muscular, neural and vascular elements. An understanding of the mechanisms that direct the coordinated development of these different elements is a central question in vertebrate evolution (Atchley and Hall, 1993). Apart from its evolutionary significance, an understanding of the mechanisms that control craniofacial development also has important medical implications because it has been estimated that craniofacial anomalies account for one third of all human congenital defects (Larsen, 1993).

In mice, there are many genes that are known to be essential for craniofacial development (for review, see Francis-West et al., 1998). Several of these genes have been demonstrated to be mutated in classical mouse mutants, including small eye (sey) (Hill et al., 1991), short ear (se) (Kingsley et al., 1992) and congenital hydrocephalus (ch) (Kume et al., 1998). Other genes such as Msxl, Mhox, Hoxa2 and Gsc have been shown to be important in craniofacial development by targeted mutagenesis using mouse embryonic stem (ES) cells (Gendron-Maguire et al., 1993; Rijli et al., 1993; Satokata and Mass, 1994; Martin et al., 1995; Rivera-Pérez et al., 1995; Yamada et al., 1995). Furthermore, they provide tools to study the genetic control of head development. In this study, we investigate the developmental mechanisms responsible for the craniofacial malformations that develop in Gsc-null mice, using mouse chimeras.

Goosecoid (Gsc) encodes a paired-like homeoprotein (Bürglin, 1994) that acts as a transcription factor (Artinger et al., 1997; Heanue et al., 1997; Danilov et al., 1998; Ferreiro et al., 1998). This homeobox-containing gene is conserved among vertebrates (Blumberg et al., 1991; Izpisúa-Belmonte et al., 1993; Stachel et al., 1993; Blum et al., 1994; SchulteMerker et al., 1994) and a functional homologue has also been described in Drosophila (Goriely et al., 1996; Hahn and Jäckle, 1996). In vertebrates, Gsc is expressed during gastrulation in regions of the embryo with axial patterning 
activity (Cho et al., 1991; Blum et al., 1992; IzpisúaBelmonte et al., 1993; Stachel et al., 1993; Schulte-Merker et al., 1994). At later stages of embryogenesis, Gsc is expressed in craniofacial regions, ventral body wall and limbs (Gaunt et al., 1993; Schulte-Merker et al., 1994; Wakamiya et al., 1997). Gsc-null mice have been generated by gene targeting in ES cells (Rivera-Pérez et al., 1995; Yamada et al., 1995). The Gsc mutants died soon after birth with multiple craniofacial defects and rib cage malformations (RiveraPérez et al., 1995; Yamada et al., 1995; Zhu et al., 1998). The craniofacial defects that were observed in these mutants correlated with the expression of Gsc in mesenchymal tissues during head organogenesis (Gaunt et al., 1993; Mallo and Gridley, 1996; Wakamiya et al., 1997). Although Gsc is likely a nuclear localized protein and therefore, must act cell autonomously, it may regulate downstream genes with non cell-autonomous activities. Indeed, in Xenopus, embryonic cells that have been injected with exogenous Gsc mRNA can recruit neighboring unmanipulated cells to participate in the formation of a secondary body axis, suggesting that exogenous Gsc has non-cell-autonomous effects (Cho et al., 1991; Niehrs et al., 1993).

To understand the mechanisms responsible for the craniofacial malformations that develop in Gsc-null mice, we have exploited the two distinct Gsc-null alleles that we had previously generated to produce morula aggregation chimeras composed of Gsc-null and wild-type cells. These mouse chimeras studies have revealed a cell-autonomous mode of action for Gsc in the developing head. However, we also found that $G s c$-null cells could contribute to the cell condensation of the tympanic ring bone of chimeras which is always missing in Gsc-null mice. We propose that this rescue is caused by the presence of wild-type precursor cells that gather the Gsc-null cells into the tympanic ring cell condensation. At later stages, gaps are found in the tympanic ring, suggesting that Gsc-null cells are not maintained after inclusion into the cell condensations.

\section{MATERIALS AND METHODS}

\section{Mice}

Mice carrying the $G s c^{f}$ and $G s c^{r}$ alleles used in this study were maintained on a C57BL/6J $\times 129 / \mathrm{SvEv}(\mathrm{B} 6 / 129)$ mixed genetic background (Rivera-Pérez et al., 1995). Both mouse strains are wildtype at the tyrosinase locus $(C / C)$. ROSAßgeo26 mice (TgR(ROSA26)26Sor) on a B6/129 mixed genetic background were purchased from the Jackson Laboratory (Bar Harbor, Maine). Swiss mice were purchased from Taconic Farms, Inc. (Germantown, NY).

\section{Gsc genotyping}

The identification of the wild type, Gsc ${ }^{f}$ and $G s c^{r}$ alleles was determined by PCR. The following primers were used to detect the three Gsc alleles: Gsc wild-type allele (782 bp), Gsc 5'wt: $5^{\prime}$ cac cag atg ctg ccc tac at $3^{\prime}$ and Gsc3'wt: $5^{\prime}$ cga ctg tct gtg caa gtc ct $3^{\prime}$. Gsc ${ }^{f}$ allele (506 bp), NeoF: $5^{\prime}$ ggc tac ccg tga tat tgc tg $3^{\prime}$ and Gsc $3^{\prime} w t$. $G s c^{r}$ allele (640 bp), NeoR: $5^{\prime}$ cct gcg tgc aat cca tct tg $3^{\prime}$ and $G s c 3^{\prime} w t$.

The PCR reaction contained $67 \mathrm{mM}$ Tris- $\mathrm{HCl} \mathrm{pH} 8.8,6.7 \mathrm{mM}$ $\mathrm{MgCl}_{2}, 170 \mathrm{mg} / \mathrm{ml} \mathrm{BSA}, 16.6 \mathrm{mM}\left(\mathrm{NH}_{4}\right)_{2} \mathrm{SO}_{4}, 0.25 \mathrm{mM}$ dNTPs, $10 \%$ DMSO, $100 \mathrm{ng}$ of each oligonucleotide and 50-100 $\mathrm{ng}$ of genomic DNA in a $20 \mu \mathrm{l}$ volume. A total of 35 cycles $\left(94^{\circ} \mathrm{C}\right.$ for 1 minute, $60^{\circ} \mathrm{C}$ for 30 seconds and $72^{\circ} \mathrm{C}$ for 1 minute) were performed in a Perkin Elmer Cetus DNA thermal cycler. A denaturing cycle of 4 minutes at $94^{\circ} \mathrm{C}$ was performed at the beginning of the 35 cycles and a final extension cycle of 7 minutes at $72^{\circ} \mathrm{C}$ was performed at the end. Each allele was amplified in independent reactions. The PCR products were visualized by gel electrophoresis in agarose and ethidium bromide staining.

\section{Generation of aggregation chimeras}

Aggregation chimeras were generated by the aggregation of morula stage embryos obtained from $G s c$ heterozygous $\left(G s c^{f /+} ; C / C \times G s c^{r /+}\right.$; $R 26 / R 26 ; C / C)$ and Swiss $\left(\mathrm{Gsc}^{+/+} ; \mathrm{clc}\right)$ matings. $\mathrm{Gsc}^{r /+} ; \mathrm{R} 26 / \mathrm{R} 26$; $C / C$ male mice were generated by crossing mice carrying the ubiquitously expressed ROSAßgeo26 (R26) transgene insertion (Friedrich and Soriano, 1991; Zambrowicz et al., 1997) with $\mathrm{Gsc}^{r /+}$ mice. Homozygosity for $R 26$ in the $G s c^{r /+}$ males was verified by crosses with wild-type females to analyze the $R 26$ genotypes of the resulting progeny.

Wild-type embryos were recovered from natural matings of Swiss mice. Embryos from Gsc heterozygous crosses were obtained either from natural matings or were obtained from matings with superovulated $\mathrm{Gsc}^{f /+}$ females. The protocol used to generate the morula aggregation chimeras follows the description given by Hogan et al. (1994). Two embryos (one obtained from the Swiss matings and one from the Gsc heterozygous matings), denuded of their zona pellucidas, were aggregated, cultured overnight, then transferred into the uterus of 2.5 day pseudopregnant females in groups of 8-10. Chimeras were collected at $14.5,15.5$ and 18.5 d.p.c.

\section{$\beta$-galactosidase histochemistry}

Transverse frozen sections of the heads of 14.5 and 15.5 d.p.c. embryos were prepared for $\beta$-gal histochemistry. To prepare frozen sections, embryos were dissected and rinsed in HBSS $(10 \mathrm{mM}$ HEPES, $1 \mathrm{mM} \mathrm{CaCl}_{2}, 1 \mathrm{mM} \mathrm{MgSO} 4,137 \mathrm{mM} \mathrm{NaCl}, 5.4 \mathrm{mM} \mathrm{KCl}$, $5.6 \mathrm{mM}$ dextrose and $0.34 \mathrm{mM} \mathrm{Na}_{2} \mathrm{HPO}_{4}$ ). The head was isolated and fixed in $3.5 \%$ paraformaldehyde at $4^{\circ} \mathrm{C}$ in HBSS for 8 hours. The heads were then transferred into increasing concentrations of sucrose $(10 \%, 15 \%$ and $25 \%)$ in HBSS at $4^{\circ} \mathrm{C}$ until they sank to the bottom of the tube (usually overnight). The heads were then embedded in OCT compound (Sakura Finetek, Inc.) on a block of dry ice. After freezing, the samples were stored at $-80^{\circ} \mathrm{C}$ until sectioning. Frozen sections of $14 \mu \mathrm{m}$ were generated using a Reichert-Jung cryostat (2800 frigocut) at $-20^{\circ} \mathrm{C}$ to $-22^{\circ} \mathrm{C}$ and collected on Superfrost/plus microscope slides (Fisher Scientific).

For $\beta$-gal histochemistry, sections were allowed to dry at room temperature for up to 1 hour and fixed for 5 minutes in freshly prepared fixation solution $(0.2 \%$ glutaraldehyde, $2 \%$ formalin, $5 \mathrm{mM}$ EGTA, $2 \mathrm{mM} \mathrm{MgCl}_{2}$ and $0.1 \mathrm{M}$ phosphate buffer $\mathrm{pH}$ 7.3). After fixation, the sections were rinsed 3 times for 20 minutes each in wash solution $\left(0.1 \%\right.$ deoxycholate, $0.2 \% \mathrm{NP} 40,2 \mathrm{mM} \mathrm{MgCl}_{2}$ and $0.1 \mathrm{M}$ phosphate buffer $\mathrm{pH} 7.3$ ) and stained overnight at $37^{\circ} \mathrm{C}$ in staining solution $(1 \mathrm{mg} / \mathrm{ml} \mathrm{X}$-gal, $5 \mathrm{mM}$ ferricyanide, $5 \mathrm{mM}$ ferrocyanide in wash solution). The next day, the sections were rinsed in the wash solution and maintained in tap water before counterstaining. The Xgal-stained sections were counterstained with eosin by a quick dip in $0.5 \%$ eosin Y (Polysciences). Subsequently, the sections were dehydrated with quick dips through an ethanol series of $70 \%, 95 \%$ and $100 \%$, two changes of xylenes, and coverslipped using Permount (Fisher).

\section{Histological analysis}

The heads of 15.5 d.p.c. embryos were isolated and immersed overnight in Bouin's fixative (Polysciences, Inc.). The specimens were washed extensively in $70 \%$ ethanol and dehydrated through a series of ethanol washes at $80 \%, 90 \%, 95 \%$ and $100 \%$ twice for 30 minutes each. Subsequently, the samples were placed in xylene for 10 minutes then in a 1:1 mixture of xylene and paraffin (Paraplast, Oxford Labware) for 20 minutes. Samples were then incubated twice in paraffin at $65^{\circ} \mathrm{C}$ for one hour each and incubated overnight in a third 
change of paraffin. After embedding, $10 \mu \mathrm{m}$ thick sections were generated and stained with hematoxylin and eosin (H\&E).

\section{Skeleton preparations}

18.5 d.p.c. fetuses were isolated by Ceasarian section and killed. The tail was removed to isolate genomic DNA for genotyping. Their skins and visceral organs were removed, then the carcass was fixed in $95 \%$ ethanol. Their skeletons were subsequently prepared by alkaline digestion and stained with Alcian blue 8GX for cartilage and Alizarin red S for bone (Kochhar, 1973).

\section{RESULTS}

\section{Generation of Gsc mouse chimeras}

To determine if Gsc acts cell autonomously during craniofacial development, mouse chimeras were generated by morula aggregation, exploiting the two distinct $G s c$-null alleles (designated $G s c^{f}$ and $G s c^{r}$ ) that had been previously generated (Fig. 1) (Rivera-Pérez et al., 1995). In this strategy, males heterozygous for the $G s c^{r}$ allele were bred with females heterozygous for the $G s c^{f}$ allele to obtain morulae. This cross results in the generation of four different $G s c$ genotypes $\left(G s c^{+/+}, G s c^{r /+}, G s c^{f /+}\right.$, and $\left.G s c^{f / r}\right)$ that can be distinguished by Southern blot (Rivera-Pérez et al., 1995) or PCR analysis (Fig. 2A,B). Previously, we demonstrated that $G s c^{f / r}$ compound heterozygotes had the same mutant phenotype as $G s c^{r / r}$ and $G s c^{f / f}$ null mutants (Rivera-Pérez et al., 1995). In addition, these two Gsc-null alleles behave the same with respect to the penetrance and expressivity of the craniofacial defects on the genetic backgrounds (C57BL/6J×129/SvEv mixed, C57BL/6J congenic and $129 / \mathrm{SvEv}$ inbred) used to maintain these mutations (Rivera-Pérez et al., 1995; J. R.-P. and R. B., unpublished data). The $\mathrm{Gsc}^{r /+}$ males used in this cross were also made homozygous for the ROSA $\beta$ geo26 (R26) transgene insertion (Friedrich and Soriano, 1991). Mice that carry $R 26$ express $\beta$-gal in a ubiquitous pattern during embryogenesis (Zambrowicz et al., 1997). Thus, cells derived from the embryos generated from this cross can be followed by X-gal staining for $\beta$-gal activity. In addition, the Gsc heterozygous males and females used in this cross were wild-type at the tyrosinase locus $(C / C)$, providing retinal pigmentation as a second independent marker to assess chimerism. Thus, all of the embryos resulting from this Gsc heterozygous cross will carry one copy of $R 26$ and have retinal pigmentation. A second cross, of Swiss mice, was simultaneously performed to produce Gsc wild-type morulae to aggregate with the embryos produced from the Gsc heterozygous matings. These Swiss embryos are wild-type for Gsc and do not carry $R 26$ and therefore are $\beta$-gal negative. In addition, they are albino and therefore lack retinal pigmentation. The morulae isolated from these two different crosses were used to generate aggregation chimeras following standards protocols. The resulting chimeras were isolated at $14.5,15.5$, and 18.5 d.p.c. for analysis. In one series of morula aggregation experiments, 78 aggregates were generated that yielded 45 (approx. 60\%) embryos and 38 (approx. 85\%) were chimeric. Thus, approximately $50 \%$ of the aggregation pairs that were generated were recovered as chimeras. This efficient procedure simultaneously yielded $G s c$-null $\leftrightarrow$ wild-type chimeras and control chimeras (see below).

The generation of aggregation chimeras with morulae

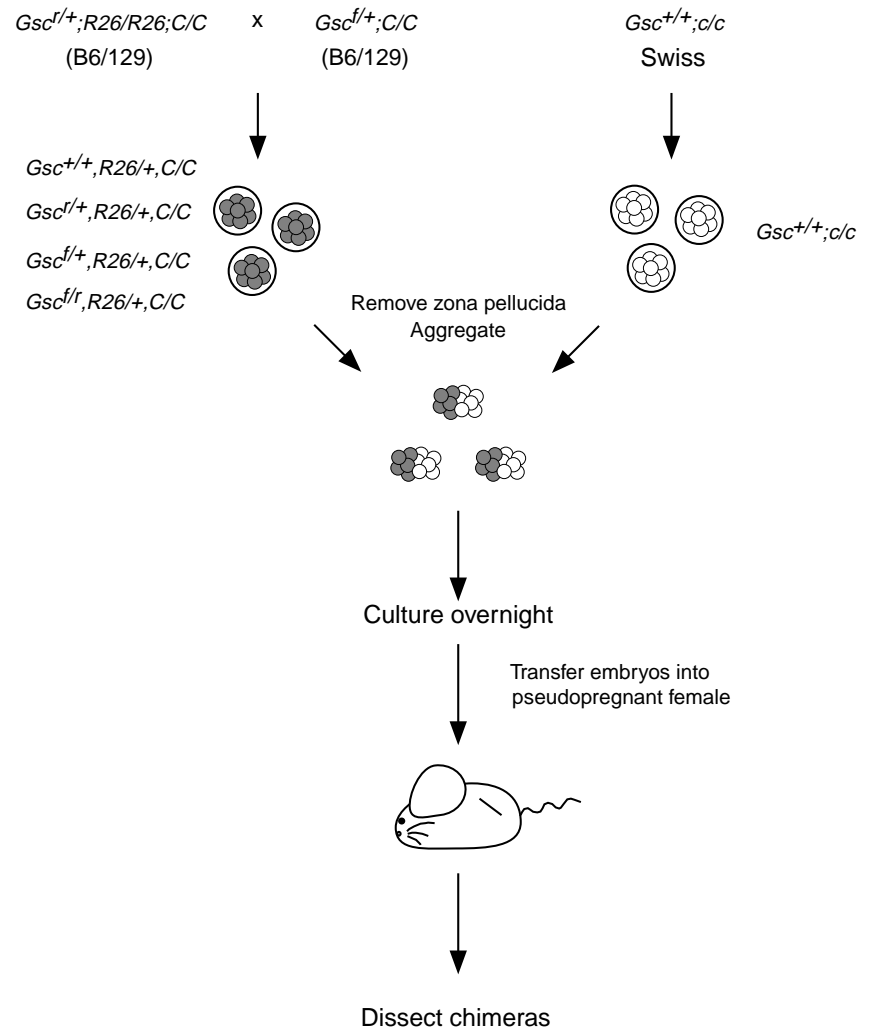

Fig. 1. Strategy to generate Gsc aggregation chimeras. Morula stage embryos were obtained from separate Gsc heterozygous and Swiss matings. The genotypes of the Gsc heterozygous parents and their genetic backgrounds are indicated at the top. The four different genotypes of the embryos resulting from the Gsc heterozygous matings are indicated. This strategy simultaneously generates mutant and control chimeras.

obtained from the Gsc heterozygous and wild-type crosses requires that the genotype of the chimeras be determined retrospectively. If only one Gsc mutant allele is used, then it becomes extremely difficult to distinguish $+/-\leftrightarrow+/+$ and $-/-$ $\leftrightarrow+/+$ chimeras because the contribution of each genotype varies between individual chimeras. However, using two distinct Gsc mutant alleles, one can unequivocally distinguish these two types of chimeras. The strategy presented here produces four types of Gsc chimeras: wild-type $\leftrightarrow$ wild-type (wild-type chimeras), $G s c^{f /+} \leftrightarrow$ wild-type and $G s c^{r /+} \leftrightarrow$ wildtype (heterozygous chimeras), and $G s c^{f / r} \leftrightarrow$ wild-type (mutant chimeras). These four types of Gsc chimeras were identified by PCR amplification of the $G s c^{+}, G s c^{r}$, and $G s c^{f}$ alleles (Fig. 2A,B). Only the $G s c$ wild-type allele will be amplified in chimeras composed of only wild-type cells (wild-type chimeras). The Gsc wild-type allele and one of the $G s c$-null alleles will be amplified in chimeras composed of wild-type and Gsc heterozygous cells (heterozygous chimeras). Finally, the $G s c$ wild-type allele and both of the two different $G s c$-null alleles will be amplified in chimeras composed of wild-type and $G s c$-null cells (mutant chimeras).

The extent of chimerism in the embryos was determined using two independent parameters: retinal pigmentation and $\beta$ gal activity. At the stages of development that were examined, the chimeric embryos had pigmented and non-pigmented cells 


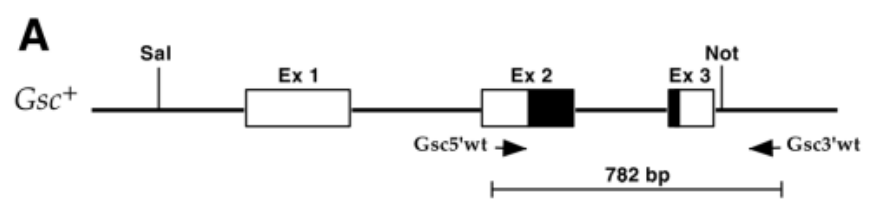

Table 1. Genotype and percentage of chimerism in E14.5 and $\mathbf{E} 15.5$ chimeras

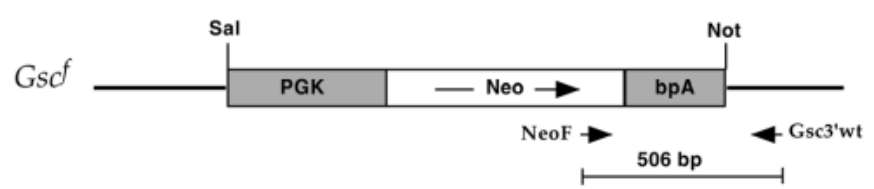

\begin{tabular}{|c|c|c|c|c|}
\hline \multirow{2}{*}{$\begin{array}{l}\% \\
\text { Chimerism* }\end{array}$} & \multicolumn{4}{|c|}{ Genotype } \\
\hline & $g s c^{+/+} \leftrightarrow+/+$ & $g s c^{f /+} \leftrightarrow+/+$ & $g s c^{r /+} \leftrightarrow+/+$ & $g s c^{f / r} \leftrightarrow+/+$ \\
\hline $1-25$ & 4 & 3 & 5 & 2 \\
\hline $26-50$ & 4 & 7 & 4 & 3 \\
\hline $51-75$ & 0 & 1 & 1 & 1 \\
\hline \multirow[t]{2}{*}{$76-99$} & 0 & 1 & 2 & 0 \\
\hline & 8 & 12 & 12 & 6 \\
\hline
\end{tabular}

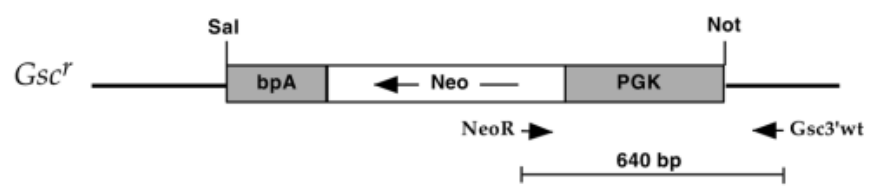

$\beta$-gal-positive cells was estimated. The percent chimerism was defined as the percentage of cells derived from the morulae from the Gsc heterozygous crosses.

\section{Gsc-null cells are excluded from Gsc-expressing regions of the nasal cartilage and middle ear}

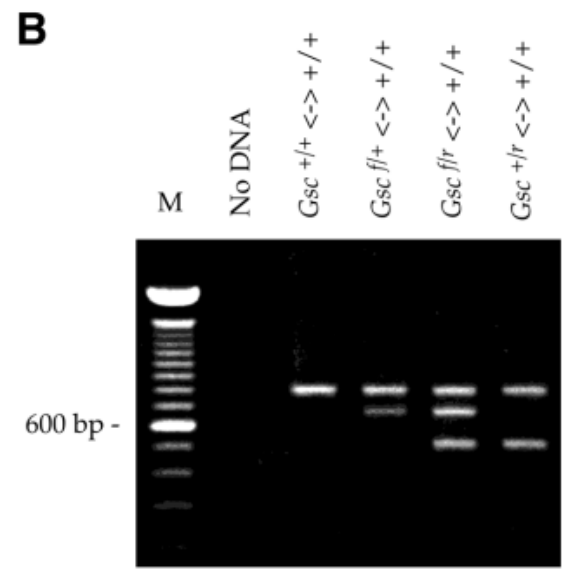

Fig. 2. Determination of chimera genotype. (A) Diagram showing the PCR strategy used to detect the three different Gsc alleles. The $G s c^{f}$ and $G s c^{r}$-null alleles are deletions of the entire $G s c$ protein coding region that differ in the orientation of the PGKneobpA cassette (Rivera-Pérez et al., 1995). The Gsc5'wt and Gsc3'wt primers amplify a Gsc wild-type fragment of $782 \mathrm{bp}$. The $G s c^{f}$ and $G s c^{r}$ alleles are detected using $5^{\prime}$ primers (NeoF or NeoR, respectively) that are present in the PGKneobpA cassette and the Gsc3'wt primer. A fragment of 506 bp is amplified from the $G s c^{f}$ allele and a fragment of $640 \mathrm{bp}$ is amplified from the $G s c^{r}$ allele. Boxes, exons; solid box, homeobox. Not, NotI; Sal, SalI. (B) PCR amplification of tail DNA from chimeras. For each chimera, the wild-type and the two Gsc-null alleles were amplified in separate reactions then pooled for analysis in ethidium bromide stained agarose gels. M, 100 bp DNA ladder (GIBCO).

in the retina of the eye. Pigmented areas corresponded to the cells contributed by the morulae derived from the Gsc heterozygous matings and non-pigmented areas corresponded to the cells contributed by the morulae derived from the wildtype matings. Variations in the chimerism were observed between the left and right eyes in some chimeras, however, this variation never accounted for more than $20 \%$. For 14.5 and 15.5 d.p.c. embryos, the percentage of $\beta$-gal cells in the regions of the head, that would normally not express Gsc, was assessed in X-gal stained sections. In 18.5 d.p.c. fetuses, the skin was removed and stained for $\beta$-gal activity and the percentage of

The chimera analysis focused upon the nasal and middle ear regions because these areas had previously been shown to be affected in all Gsc-null mice (Figs 3A,B; 4A,B). To visualize the $\beta$-gal positive cells (those derived from the embryos of the Gsc heterozygous matings) of the chimeras, X-gal histochemistry with eosin counterstaining was performed on frozen sections. To validate the $R 26$ marker in the craniofacial region, $R 26$ heterozygous embryos were assayed for $\beta$-gal activity. Strong $\beta$-gal activity was observed in the majority of the tissues analyzed, including mesenchymal tissue, cartilage and epithelia of the nose and middle ear (Figs 3C, 4C). Mineralized bone had undetectable $\beta$-gal activity and neural tissue had a spotted $\beta$-gal pattern (data not shown). The lack or variability of $\beta$-gal activity in these tissues could be due to tissue-specific differences in the expression of the transgene or in the case of bone it may reflect the high content of extracellular matrix in this tissue. Wild-type embryos were also stained for $\beta$-gal activity as negative controls to visualize potential endogenous $\beta$-gal activity in the areas of interest. Faint $\beta$-gal activity was detected only in the choroid plexus and in the lens of the eye (data not shown).

To determine if $G s c$-null cells behaved differently from wild-type cells during craniofacial development, the distribution of $\beta$-gal-positive cells was compared in the heads of 14.5 and 15.5 d.p.c. mutant and control chimeras. A total of 38 chimeras at 14.5 and 15.5 d.p.c. were obtained from three independent experiments (Table 1). The heads of six mutant $\left(G s c^{f / r} \leftrightarrow \mathrm{wt}\right)$, six heterozygous $\left(G s c^{f /+}\right.$ or $\left.G s c^{r /+} \leftrightarrow \mathrm{wt}\right)$, and one of the wild-type (wt $\leftrightarrow \mathrm{wt}$ ) chimeras were sectioned and the pattern of $\beta$-gal staining analyzed. The overall contribution of $\beta$-gal-positive cells in these chimeras ranged from $20 \%$ to $70 \%$. The pattern of $\beta$-gal staining in the wild-type and heterozygous control chimeras was comparable. In the control chimeras with approximately $50 \% \beta$-gal-positive cells, a homogeneously mixed pattern of $\beta$-gal staining was observed in all tissues with no bias for $\beta$-gal-positive cells in any region (Figs 3D, 4D). These results suggest that Gsc heterozygous cells behave in a manner that is equivalent to wild-type cells in the fetal head.

$G s c$-null mutants lack the anlagen of the turbinal bones and the ventrolateral walls of the nasal cavity (Fig. 3A,B) (RiveraPérez et al., 1995; Yamada et al., 1995). In the nasal region of 

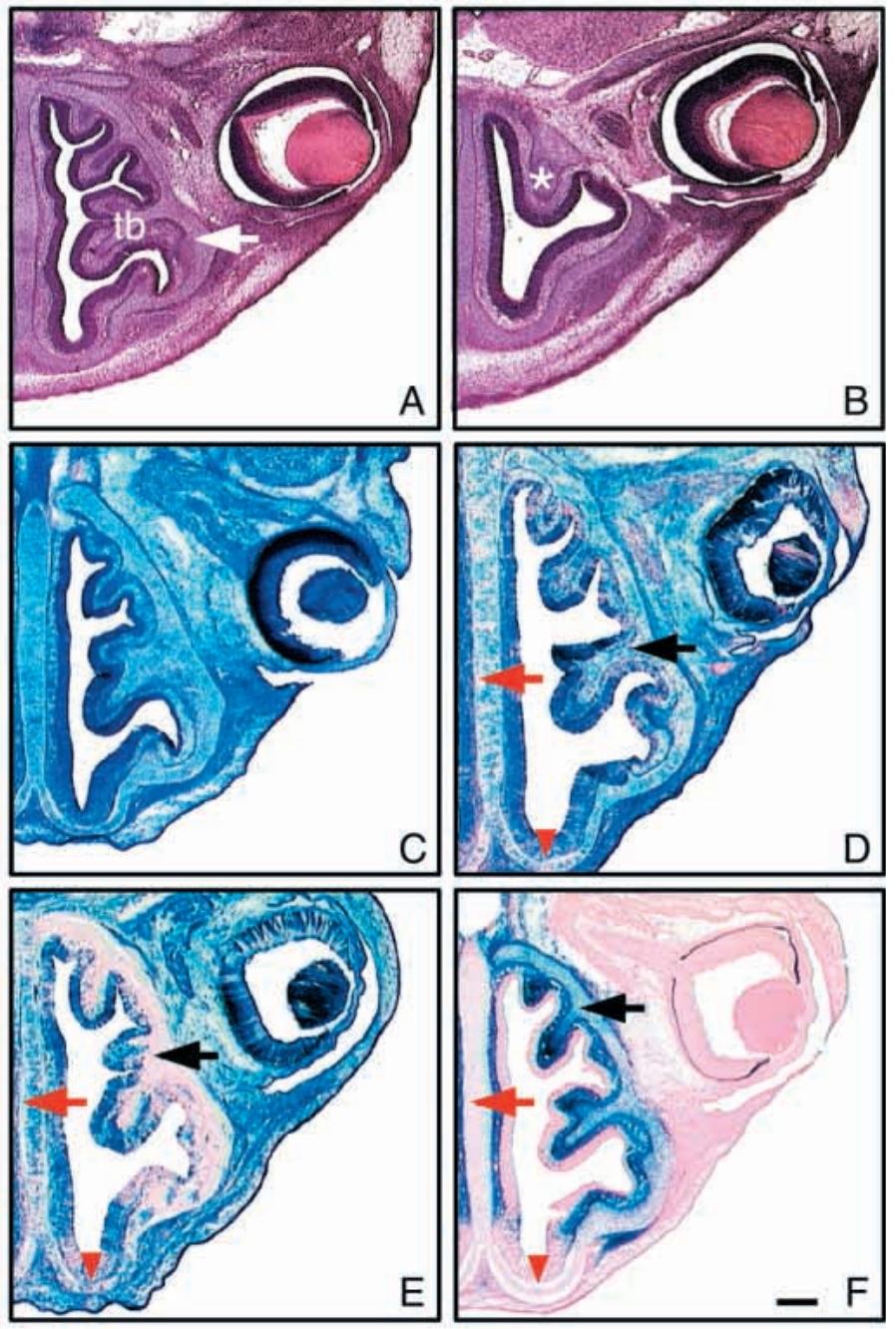

Fig. 3. Development of the nasal capsule of Gsc chimeras. (A-F) Transverse sections of 15.5 d.p.c. mouse embryos. $(A, B)$ Hematoxylin and eosin staining. (C-F) $\beta$-gal histochemistry. (A) Wild-type embryo with well formed nasal capsule and turbinals (tb). Nasal capsule cartilage (arrow). (B) Gsc-null embryo showing underdeveloped turbinals (asterisk) and nasal capsulae walls (arrow).

(C) Ubiquitous $\beta$-gal activity in a $R 26$ heterozygous embryo.

(D) Control Gsc heterozygous chimera showing a homogeneous distribution of Gsc-heterozygous (blue) and wild-type cells (pink). This fine chimerism is seen in the cartilage of the nasal septum (red arrow), and the ventral (red arrowhead) and dorsal (black arrow) regions of the nasal capsule. (E) Exclusion of Gsc-null cells (blue) in the dorsal (black arrow) nasal cartilage but not in the septum (red arrow) or the ventral (red arrowhead) nasal cartilage. (F) Gsc-specific $\beta$-gal staining in a $G s c^{l a c Z}$ heterozygous embryo. The dorsal nasal cartilage (black arrow) expresses high levels of $\beta$-gal activity, as does the lamina propia of the olfactory epithelium. However, no $\beta$-gal activity is detected in the ventral (red arrowhead) nasal cartilage or the cartilage of the septum (red arrow). This pattern mimics the endogenous pattern of $G s c$ expression. Bar, $0.5 \mathrm{~mm}$.

the $G s c$-null $\leftrightarrow$ wild-type chimeras, the anlagen of the turbinal bones (Fig. 3E) and the ventrolateral walls of the nasal capsule (not shown) were well formed. Interestingly, Gsc-null cells were excluded from the dorsal portion of the cartilaginous nasal capsule (Fig. 3E). However, individual or small patches
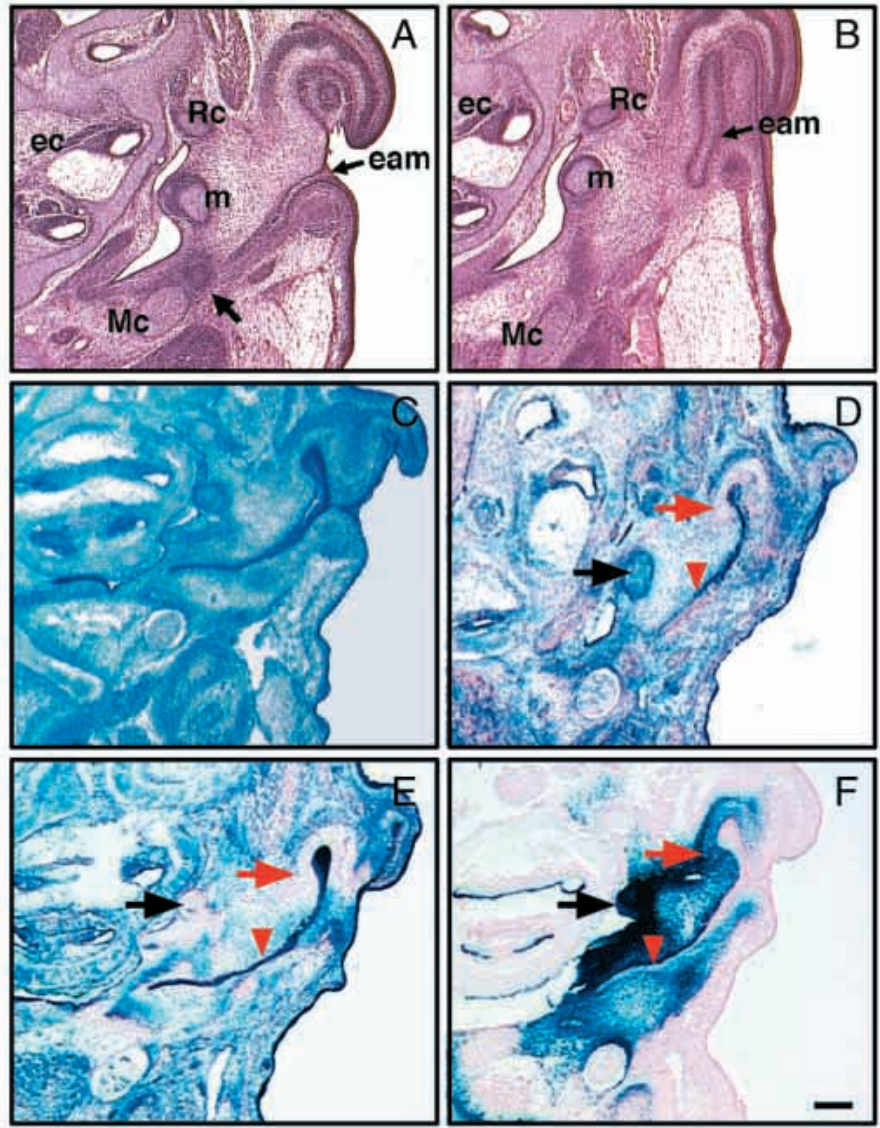

Fig. 4. Development of the middle ear region of Gsc chimeras. (A-F) Transverse sections of 15.5 d.p.c. mouse embryos. $(\mathrm{A}, \mathrm{B})$ Hematoxylin and eosin staining. (C-F) $\beta$-gal histochemistry. (A) Wild-type embryo with well formed external acoutic meatus (eam). The cell condensation (arrow) that will give rise to the tympanic ring is adjacent to Meckel's cartilage. (B) Gsc-null embryo that lacks a fully formed eam. The putative cell condensation that may give rise to the tympanic ring is adjacent to Meckel's cartilage.

(C) Ubiquitous $\beta$-gal activity in a $R 26$ heterozygous embryo.

(D) Control Gsc heterozygous chimera showing a homogeneous distribution of Gsc heterozygous (blue) and wild-type cells (pink). (E) Gsc mutant chimera with a well formed eam (red arrowhead). Exclusion of $G s c$-null cells (blue) in the cartilage of the malleus (black arrow) and the mesenchyme adjacent to the eam (red arrow). (F) $G s c$-specific $\beta$-gal activity in a $G s c^{l a c Z}$ heterozygous embryo. The malleus (black arrow) cartilage and mesenchyme (red arrow) surrounding the eam (red arrowhead) express high levels of $\beta$-gal activity. ec, ear capsule; m, malleus; Mc, Meckel's cartilage; Rc, Reichert's cartilage. Bar, $0.5 \mathrm{~mm}$.

of $G s c$-null cells were observed in the cartilage of the nasal capsulae as one moved more ventrally. In the ventral portion of the nasal capsule, the proportion of Gsc-null cells matched the overall contribution of these cells in the chimera and there was an even mixing of Gsc-null and wild-type cells (Fig. 3E). $G s c$-null cells were also well represented and mixed with wildtype cells in the cartilage of the nasal septum and in the nasal epithelium of the entire nasal cavity.

In the middle ear region of Gsc-null mutants the external acoustic meatus forms a shallow depression instead of extending towards the direction of Meckel's cartilage, 
resulting in the absence of the tympanic membrane (Fig. 4A,B) (Rivera-Pérez et al., 1995; Yamada et al., 1995). In the $G s c$-null $\leftrightarrow$ wild-type chimeras, the external acoustic meatus (Fig. 4E) was well developed. Gsc-null cells were well represented in the epithelial cells of the external acoustic meatus and the cartilage of the ear capsulae (Fig. 4E). In addition, the Gsc-null and wild-type cells were well mixed. However, the mesenchymal cells surrounding the external acoustic meatus were mostly deficient in Gsc-null cells in comparison to control chimeras (Fig. 4D,E). The cartilage anlage of the malleus also showed this deficiency of Gsc-null cells. Thus, at 14.5 and 15.5 d.p.c., Gsc-null cells were preferentially excluded from specific regions of the heads of $G s c$-null $\leftrightarrow$ wild-type chimeras.

The expression pattern of Gsc mRNA during craniofacial development has been assessed using radiolabeled probes on sectioned embryos (Gaunt et al., 1993). To follow Gscexpressing cells during development more easily, a lacZ gene, was introduced into the Gsc locus by gene targeting in mouse ES cells (M. W. and R. R. B., unpublished data). Mice heterozygous for this $G s c^{l a c Z}$ allele are normal and express $\beta$ gal during craniofacial development in a $G s c$-specific pattern (Figs 3F, 4F). The details of these mice will be published elsewhere. To assess the significance of the differential distribution of $G s c$-null and wild-type cells in the $G s c$-null $\leftrightarrow$ wild-type chimeras, we compared these results to the $\beta$-gal staining pattern of comparable sections of GsclacZ heterozygous embryos (Figs 3 and 4). The comparison of Gscnull $\leftrightarrow$ wild-type chimeras and $G s c^{\text {lac } Z}$ mice revealed a striking correlation between the pattern of Gsc-directed $\beta$-gal activity of the $G s c^{l a c Z}$ allele and the areas in which $G s c$-null cells were preferentially excluded in the chimeras. As shown in Fig. 3F, Gsc is not expressed in the cartilage of the nasal septum or in the ventral cartilage of the nasal capsule. In the Gsc-null $\leftrightarrow$ wild-type chimeras, these areas contained a significant proportion of $G s c$-null cells that were well mixed with wildtype cells (Fig. 3E). In contrast, Gsc is expressed in the dorsal portion of the nasal capsule, including both cartilage and mesenchyme. This is precisely the region in which Gsc-null cells were absent in the chimeras (Fig. 3E). Interestingly, between the ventral and dorsal regions of the nasal capsulae, at the transition between Gsc non-expressing and Gsc expressing cells, respectively, small clusters of Gsc-null cartilage cells were present in the chimeras, suggesting a dorsoventral action for Gsc in the nasal capsule. In the middle ear region of $G s c^{\text {lac } Z}$ heterozygotes, $\beta$-gal activity was detected in the mesenchymal cells surrounding the external acoustic meatus and the cartilage anlage of the malleus (Fig. 4F). These were the same regions of the $G s c$-null $\leftrightarrow$ wild-type chimeras that were preferentially composed of wild-type cells (Fig. 4E). Thus, Gsc-null cells are preferentially excluded from specific $G s c$-expressing craniofacial regions of $G s c$-null $\leftrightarrow$ wild-type chimeras.

\section{Tympanic ring development in Gsc-null $\leftrightarrow$ wild-type chimeras}

Skeletal analysis of Gsc-null mice reveals that many bones and cartilages are affected morphologically. The determination of the causal mechanisms responsible for these skeletal defects requires an examination of how these abnormalities are produced during development. We chose to study the development of the tympanic ring bone in Gsc chimeras because it is always absent in Gsc-null mice (Rivera-Pérez et al., 1995; Yamada et al., 1995).

The tympanic ring is a semicircular membranous bone that supports the tympanic membrane. During development, the tympanic ring is first evident at 13.5 d.p.c. as a cell condensation adjacent to the Meckel's cartilage (Mallo and Gridley, 1996). This condensation, initially grows in a dorsocaudal direction and then rostrally to form a C-shaped structure. A fully ossified tympanic ring is evident by 17.5 d.p.c. (Mallo and Gridley, 1996).

To determine at which stage defects in the formation of the tympanic ring bone of $G s c$-null mice occurred, a histological analysis of its cell condensation was performed. In 14.5 d.p.c. Gsc-null embryos, the characteristic circular cell condensation of the tympanic ring adjacent to the Meckel's cartilage was not observed when compared to wild-type embryos (data not shown). However, at 15.5 d.p.c. an irregularly shaped cell condensation was observed between the Meckel's and malleous cartilages (Fig. 4A,B). This condensation probably represents the precursor of the gonial bone that develops in close association with the tympanic ring at its most rostral portion and is present in Gsc-null mice. However, we could not rule out that is also included vestiges of the tympanic ring condensation. Unfortunately, the lack of a marker specific for the tympanic ring cell condensation precludes an unambiguous conclusion. Nonetheless, these results indicate that the lack of a tympanic ring bone in Gsc-null mutants can be traced to defects at the cell condensation stage.

In 15.5 d.p.c. Gsc-null $\leftrightarrow$ wild-type chimeras, a defined tympanic ring cell condensation was observed. Analysis of the tympanic ring cell condensation in serial sections revealed that both $G s c$-null and wild-type cells were present (Fig. 5). In some sections the chimeric condensation was predominantly composed of wild-type cells, a mixture of both wild-type and $G s c$-null cells, or predominantly Gsc-null cells. The distribution of Gsc-null and wild-type cells in the tympanic ring cell condensation did not reveal extensive intermingling, rather the two genotypes were generally segregated in cell clusters. Thus, in the presence of wild-type cells, Gsc-null cells have the capacity to participate in the formation of the tympanic ring condensation.

To examine the phenotypic consequences of a chimeric tympanic ring cell condensation, chimeras were generated and their skulls analyzed at 18.5 d.p.c. (Fig. 6). Whereas the tympanic ring bones of the control chimeras were always of normal morphology, defects in the morphology of the tympanic ring bones were evident in three Gsc-null $\leftrightarrow$ wild-type chimeras with greater than $50 \%$ Gsc-null cells. These defects were characterized by a reduction of or loss of parts of the bone that could vary on each side of the same chimera. In one chimera containing approximately $50 \%$ Gsc-null cells, a small portion of bone was missing at approximately one third the length of the tympanic ring (Fig. 6A,C,E). In another chimera with $70 \%$ Gsc-null cells, two discontinuous pieces of bone were found in place of the single tympanic ring on both the right and left sides of the fetus (Fig. 6B,D,F). Although the precise genotypic composition of the tympanic ring bone cells could not be determined in these skeletal preparations, these results suggest that the skeletal defects were caused by the presence of Gsc-null cells during its development. 


\section{Nasal capsules and mandibles of Gsc-null $\leftrightarrow$ wild- type chimeras}

We also examined the nasal capsules and mandibles of 18.5 d.p.c. $G s c$-null $\leftrightarrow$ wild-type chimeras to examine how Gsc acts in these skeletal structures (Fig. 7). In wild-type mice at 18.5 d.p.c., the nasal capsules have well-formed chambers that are divided by the anlagen of the turbinal bones. However, in Gscnull mice the anlagen of the turbinal bones are essentially absent (Rivera-Pérez et al., 1995). Three 18.5 d.p.c. Gsc-null chimeras were examined that were composed of 50,70 and $90 \%$ Gsc-null cells. The nasal capsule of the Gsc-null chimera with 50\% Gsc-null cells appeared to be similar in morphology to the wild-type control. However, the nasal capsule of the chimera with $70 \%$ Gsc-null cells had less extensive chambers. The nasal capsule of the chimera with $90 \%$ Gsc-null cells looked identical to the Gsc-null nasal capsule. These results also support the idea that Gsc acts cell autonomously in the development of the nasal capsule.

In wild-type mice at 18.5 d.p.c., the mandibles have three processes, the coronoid, condilar and angular processes. In addition, Meckel's cartilage inserts between the condilar and angular processes in an opening initiating on the inner surface of the mandible. This opening or groove extends about one third to just less than one half the length of the mandible. Meckel's cartilage is then enclosed by bone extending towards the incisor. In Gsc-null mice, the coronoid and angular processes are severely reduced in size and the mandible is shortened in length (Rivera-Pérez et al., 1995). Furthermore, Meckel's cartilage is not enclosed by the bone of the mandible but is embedded in a groove that extends along the entire length of the mandible. The mandibles of the Gsc-null chimeras had mutant phenotypes that were intermediate between the wild-type and Gsc-null controls that correlated with the proportion of Gsc-null cells in the chimeras (Fig. 7). For example, the mandible of the Gsc-null chimera with $50 \%$ Gsc-null cells generally appeared normal but there was a reduction in size of the angular process. In addition, the groove for Meckel's cartilage extended half the length of the left and right mandibles. In the mandible of the Gsc-null chimera with $70 \%$ Gsc-null cells both the coronoid and angular processes were reduced in size though clearly larger than the Gsc-null control. In addition, the groove for Meckel's cartilage extended approximately two thirds the length of the mandible. The mandible of the chimera with $90 \%$ Gsc-null cells looked identical to the Gsc-null mandible. The abnormalities detected in the mandibles of the Gsc-null chimeras also support a cell-autonomous action for Gsc.

\section{DISCUSSION}

In this study, the behavior of $G s c$-null cells was examined in mouse chimeras. The two distinct Gsc-null alleles that had been previously generated by gene targeting were exploited to generate these chimeras by the classic method of morula aggregation (Tarkowski, 1961; Mintz, 1962). This simple method has been used for analysis of homozygous mutants that are viable and fertile (Grüneberg and McLaren, 1972). However, for lethal mutations in which the mutant embryos can only be derived from heterozygous parents, the use of two distinct mutant alleles is necessary (Quinn et al., 1996). Thus, the use of the two distinct $G s c$-null alleles provided tools for identifying the chimeras composed of Gsc-null and wild-type cells. The two different Gsc-null alleles had previously been generated separately using two distinct gene targeting vectors and were derived from chimeras from independent blastocyst injections. Current gene targeting methods using selectable marker cassettes flanked by loxP or Frt sequences provide a simpler means of generating a second mutant allele by simply breeding mice heterozygous for the first targeting event to deletor mice expressing cre recombinase or flpase ubiquitously to remove the selectable marker sequences (Schwenk et al., 1995; Dymecki, 1996).

The strategy we have developed offers several advantages over other methods to generate mouse chimeras such as the generation of mutant embryonic stem (ES) cell lines for blastocyst microinjection or aggregation with morulae (Wood et al., 1993). First, it is not necessary to derive ES cell lines from mutant blastocysts or by a second gene targeting manipulation or by selection for rare gene conversion events with high drug concentrations (te Riele et al., 1990; Rashbass et al., 1991; Weitzer et al., 1995). Because in vitro manipulations of ES cells can introduce unwanted genetic alterations (Liu et al., 1997), one must always examine multiple mutant ES cell lines in a chimera study (Rashbass et al., 1991; Chen and Behringer, 1995). Morula stage embryos are normal except for the mutations they inherit. Second, whereas ES cells are biased against contributing to extraembryonic tissues (Beddington and Robertson, 1989), the blastomeres of embryos up to the 8 cell stage are totipotent (Kelly, 1977). Thus, a mutant phenotype can be analyzed in both embryonic and extraembryonic tissues. Third, like ES cell-morula aggregations, morula-morula aggregations are simple and do not require expensive micromanipulation equipment (Wood et al., 1993). Finally, in our strategy, both the experimental and control chimeras are generated in the same experiment under the same conditions.

\section{Gsc functions cell autonomously during craniofacial development}

The generation of chimeras creates animals in which mutant and wild-type cells can interact in vivo. One clear indication that a mutation acts cell autonomously is a bias in the distribution of mutant and wild-type cells in tissues that would normally express the gene product (Chen and Behringer, 1995; Wilson et al., 1995; Ciruna et al., 1997; Deng et al., 1997). When the distribution of Gsc-null cells in the Gsc-null $\leftrightarrow$ wildtype chimeras was compared with the distribution of cells in the control chimeras, a preferential exclusion of $G s c$-null cells in specific nasal cartilage and middle ear regions was observed. This exclusion of Gsc-null cells became even more evident when the distribution of cells in Gsc-null $\leftrightarrow$ wild-type chimeras was compared with the Gsc-directed $\beta$-gal expression pattern of the $G s c^{l a c Z}$ mice.

A comparison of the regions that were positive or negative for Gsc expression in the same specimen provided an exceptional internal control in these experiments. This was readily observed upon comparison of the cartilage of the nasal septum and the turbinate region of the nasal capsula. The nasal septum is negative for Gsc expression and had a fine distribution of Gsc-null and wild-type cells. However, the 
Fig. 5. Behavior of Gsc-null mesenchyme cells in Gsc chimeras. (A,B) Transverse sections of X-gal stained middle ear regions of 15.5 d.p.c. mouse embryos. Ventral at the bottom. (A) GsclacZ heterozygous embryo, showing the location of the tympanic ring mesenchymal condensation (arrow) within the Gsc expression domain (blue). (B) Gsc mutant chimera, showing the participation of Gscnull cells (blue) in the tympanic ring mesenchymal condensation (arrow). Boxed area shown at higher magnification in inset. Mc, Meckel's cartilage.
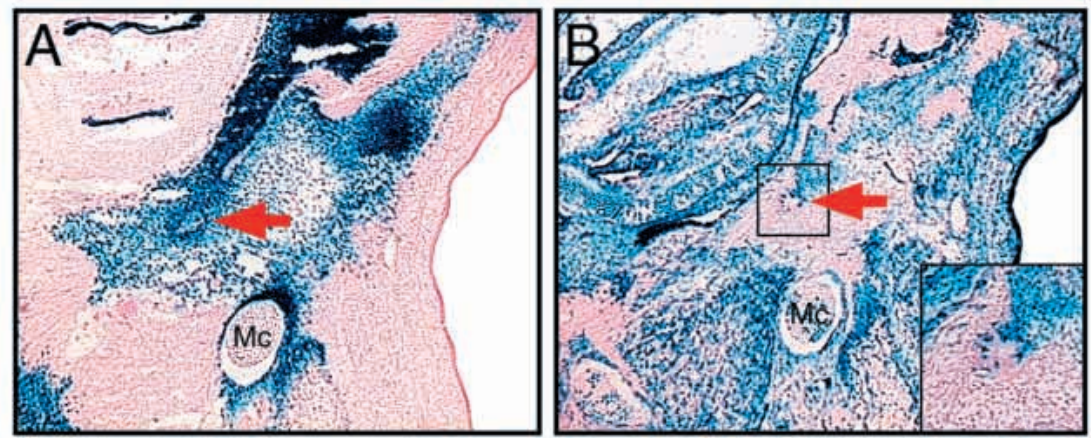
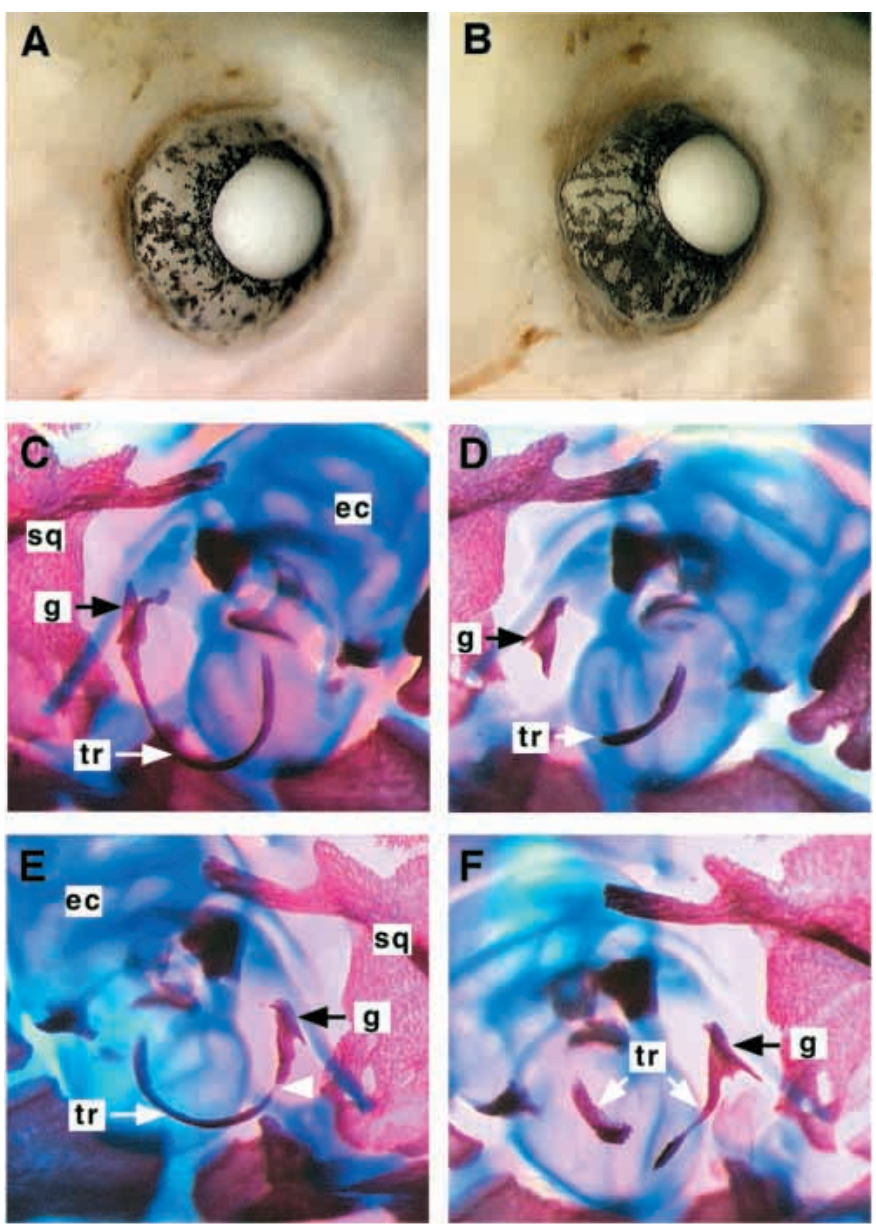

Fig. 6. Analysis of tympanic ring bone development in Gsc chimeras. (A,B) Eyes of two different 18.5 d.p.c. Gsc mutant chimeras whose eyelids have been removed. The chimera in A was judged, by retinal pigmentation, to be composed of approximately $50 \%$ Gsc-null cells (pigmented patches). The chimera in B is composed of approximately $70 \%$ Gsc-null cells. (C-F) Skeletal preparations showing the left and right tympanic ring bones of the two chimeras shown in $\mathrm{A}(\mathrm{C}$ and $\mathrm{E})$ and $\mathrm{B}(\mathrm{D}$ and $\mathrm{F})$. The tympanic rings have abnormalities that correlate with the amount of Gsc-null cells present in the chimeras. A small gap is observed in $\mathrm{E}$ (arrowhead), whereas one fragment is present in D and two fragments are present in F. ec, ear capsule; g, gonial bone; sq, squamosal bone; tr, tympanic ring.

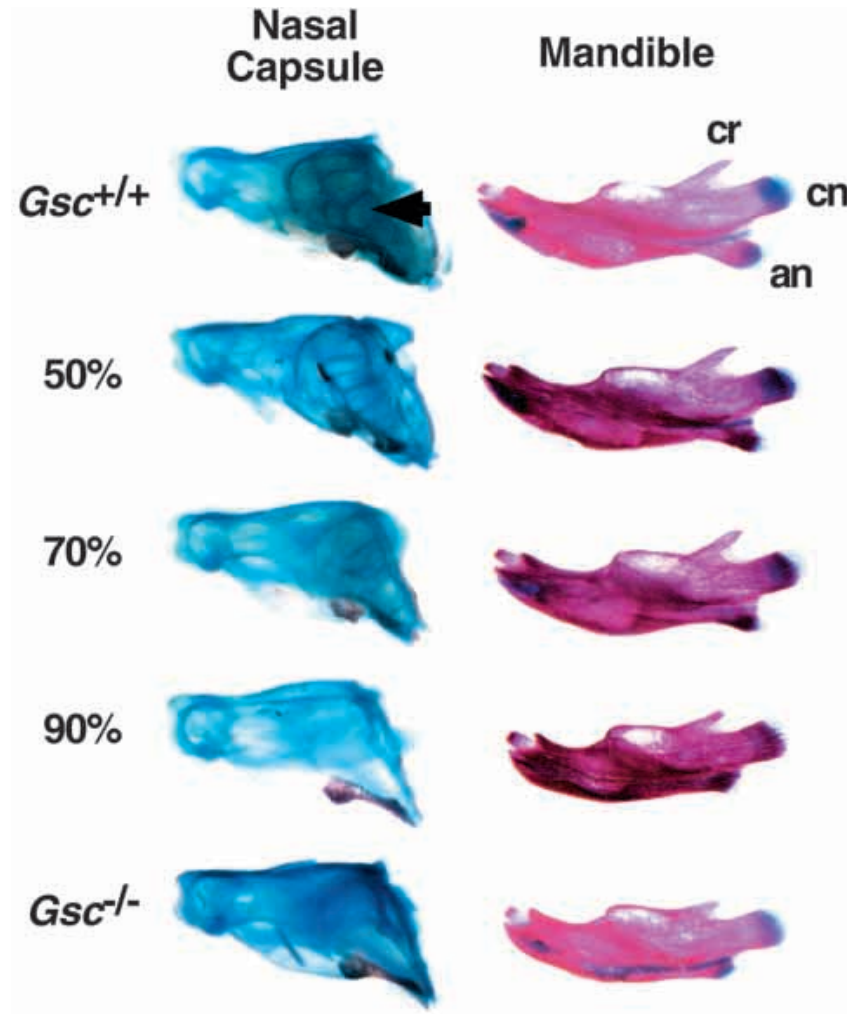

Fig. 7. Analysis of nasal capsules and mandibles in Gsc chimeras. The dissected nasal capsules (lateral view, snout pointing to left) and left mandibles (lateral view) of wild-type (+/+), Gsc-null (-/-), and three $G s c$-null chimeras composed of 50, 70 and $90 \%$ Gsc-null cells. The wild-type nasal capsule has numerous well-formed chambers divided by the turbinal bone anlagen (arrow). The Gscnull nasal capsule is essential devoid of these chambers. The nasal capsules of the chimeras vary in severity correlating with increasing amounts of $G s c$-null cells. The wild-type mandible has well-formed coronoid and angular processes with Meckel's cartilage embedded within the bone. The Gsc-null mandible has reduced coronoid and angular processes. In addition, Meckels cartilage is only partially embedded in the bone in a groove that extends along the full length of the mandible. The mandibles of the chimeras also vary in severity correlating with increasing amounts of Gsc-null cells. cr, coronoid; cn, condilar; an, angular. 
turbinate region, which is positive for Gsc expression, was composed predominantly of wild-type cells.

The intricate morphology of the middle ear region, makes the analysis of this region more difficult. However a selection against $G s c$-null cells was also observed. Thus, the mesenchymal tissues adjacent to the external acoustic meatus which are positive for Gsc expression showed a negative selection for Gsc-null cells, whereas other mesenchymal tissues in the same region which are negative for Gsc expression, showed a homogeneous distribution of Gsc-null and wild-type cells. These results demonstrate a cellautonomous function for $G s c$ in the nasal cartilage and in mesenchymal tissues of the middle ear.

Regardless of the presence of wild-type cells, the nasal capsules and mandibles of the Gsc-null chimeras showed defects similar to the Gsc-null mice that varied in severity depending upon the proportion of Gsc-null cells. This also indicates that $G s c$ acts in a cell-autonomous manner later in the turbinal bone anlagen and also in the mandible. Earlier in development the affected regions of the nasal capsule were essentially only composed of wild-type cells. The nasal capsule defects observed in 18.5 d.p.c. $G s c$-null chimeras with greater than $50 \%$ Gsc-null cells therefore suggest that there were insufficient wild-type cells present to compensate for the loss of the Gsc-null cells.

The exclusion of Gsc-null cells from specific structures in $G s c$-null $\leftrightarrow$ wild-type chimeras suggest that Gsc is required for the birth, proliferation or survival of Gsc-expressing cells. However, these defects are limited to regions that express Gsc, as shown when chimeras are compared with $G s c^{l a c Z}$ mice. Thus, the skeletal defects observed in Gsc-null mice may be a reflection of a local defective environment in which fewer precursor cells are available. A similar function has been proposed for Drosophila Gsc (D-Gsc). In this case, D-Gsc has been suggested to be involved in the birth or survival of precursors of the first esophageal ganglion in the somatogastric nervous system (Hahn and Jäckle, 1996).

\section{Analysis of tympanic ring bone development}

Skeletal elements develop through several stages that include epithelial-mesenchymal interactions, cell condensation, differentiation and morphogenesis (Hall and Miyake, 1992, 1995). We wished to address how the skeletal malformations in $G s c$-null mice were generated during development. We focused our attention on the tympanic ring bone, a membranous bone that supports the tympanic membrane. The simple semicircular shape of the tympanic ring and its total absence in Gsc-null mice made it a good candidate for this analysis as compared, for example, to the dentary, which has a more complex morphology and is only partially affected in the Gsc-null mice (Rivera-Pérez et al., 1995; Yamada et al., 1995).

A histological analysis of the tympanic ring bone in Gscnull embryos revealed that the tympanic ring defects were first observed at the cell condensation stage. In Gsc-null embryos at 14.5 d.p.c., a distinctive tympanic ring cell condensation was not found. Instead a diffused and irregular cell condensation that appeared to be the cell condensation of the gonial bone was observed at 15.5 d.p.c. Thus, defects in tympanic ring development were already evident at the cell condensation stage.
In control chimeras, analysis of the tympanic ring cell condensation revealed the presence of cells derived from the two genotypes that made up the chimera. This was evident by the presence of both $\beta$-gal-positive and $\beta$-gal-negative cells in the cell condensation. The presence of both types of cells reveals a multiclonal origin for this bone. A similar result was obtained by Moore and Mintz during the clonal analysis of craniofacial skeletal elements using GPI analysis (Moore and Mintz, 1972). Analysis of $G s c$-null $\leftrightarrow$ wild-type chimeras revealed the presence of a well defined tympanic ring cell condensation. The tympanic ring cell condensation, was found to contain both Gsc-null and wild-type cells in some sections along its length, but in other sections Gsc-null cells made up the whole cell condensation. Thus in the presence of wild-type cells, Gsc-null cells were able to form a tympanic ring cell condensation. These results suggest a non cell-autonomous function for Gsc during the formation of the tympanic ring. Indeed a non cell-autonomous function for Gsc has been suggested by Xenopus experiments where ectopic expression of Gsc resulted in the recruitment of wild-type cells into a secondary axis (Niehrs et el., 1993). However, a careful examination of the chimeric tympanic ring cell condensation, reveals that when both $G s c$-null and wild-type cells are present, they remain segregated in clusters instead of forming a well mixed composite as observed in the control chimeras. In addition, the presence of a tympanic ring cell condensation composed of only $G s c$-null cells in some sections of $G s c$-null $\leftrightarrow$ wild-type chimeras suggests that Gsc-null cells do not require wild-type cells to form this cell condensation. Futhermore, in the 18.5 d.p.c. chimeras, regional tympanic ring bone defects were observed in chimeras with a high percentage of $G s c$-null cells. These results argue for a cell-autonomous function for Gsc in tympanic ring bone development.

These results present a paradox. On one hand, the presence of wild-type cells rescues the capacity of $G s c$-null cells to form a tympanic ring cell condensation, suggesting a non cellautonomous action for Gsc. On the other hand, the lack of cell mingling in the cell condensation and later regional gaps in the tympanic ring bone suggest a cell-autonomous function of the gene. Two explanations could account for these results. In one scenario, Gsc has both non cell-autonomous and cellautonomous functions in mesenchymal cells. A non cellautonomous function of Gsc could rescue the capacity of Gscnull cells to form the tympanic ring cell condensation, whereas a cell-autonomous function would block their capacity to intermingle with wild-type cells. This hypothesis would require that Gsc controls the expression of at least two proteins, one that acts within and one that acts between cells. An alternative explanation can be considered if the rescue of the tympanic ring condensation acted at the cellular rather than at the molecular level. Condensation size has been suggested to be controlled within tight upper and lower limits (Grüneberg, 1963; Hall and Miyake, 1992). If the cell condensation is too small a skeletal element will not form, whereas if it is too large, it will lead to abnormally large skeletal elements that are initiated early (Hall and Miyake, 1992). This suggestion is based upon studies of the mutant congenital hydrocephalous (ch). In the ch mutant, a smaller cell condensation led to the absence of tracheal cartilages, whereas a larger one resulted in a massive zygomatic bone that developed earlier (Grüneberg and Wickramaratne, 1974). This 
mechanism has also been proposed to explain the presence of ectopic cartilages in several craniofacial mutants (Smith and Schneider, 1998). In the case of Gsc-null $\leftrightarrow$ wild-type chimeras, the presence of $G s c$-null cells in the tympanic ring cell condensation could be explained simply by the availability of more precursor cells in the chimeras to form the cell condensation. In Gsc-null $\leftrightarrow$ wild-type chimeras, this deficiency is corrected depending upon the availability of precursors along the tympanic ring cell condensation. This hypothesis reconciles both, a cell-autonomous function for Gsc during craniofacial development and partial rescue of the tympanic ring bone without implying a non cell-autonomous function for Gsc.

We thank Dr Daniel Carson and the members of his laboratory for use of their cryostat and Dr Akihiko Shimono for advice in the generation of cryosections. This study was supported by grants from the International Human Frontiers in Science Program and the National Institutes of Health (DE12705) to R. R. B.

\section{REFERENCES}

Artinger, M., Blitz, I., Inoue, K., Tran, U. and Cho, K.W. (1997). Interaction of Goosecoid and Brachyury in Xenopus mesoderm patterning. Mech. Dev. 65, 187-196.

Atchley, W. and Hall, B. K. (1991). A model for development and evolution of complex morphological structures. Biol. Rev. 66, 101-157.

Beddington, R. S. and Robertson, E. J. (1989). An assessment of the developmental potential of embryonic stem cells in the midgestation mouse embryo. Development 105, 733-737.

Blum, M., Gaunt, S. J., Cho, K. W. Y., Steinbeisser, H., Blumberg, B., Bittner, D. A. and De Robertis, E. M. (1992). Gastrulation in the mouse: The role of the homeobox gene Goosecoid. Cell 69, 1097-1106.

Blum, M., De Robertis, E. M., Kojis, T., Heinzmann, C., Klisak, I., Geissert, D. and Sparkes, R. S. (1994). Molecular cloning of the human homeobox gene Goosecoid (GSC) and mapping of the gene to human chromosome 14q32.1. Genomics 21, 388-393.

Blumberg, B., Wright, C. V. E., De Robertis, E. M. and Cho, K. W. Y. (1991). Organizer-specific homeobox genes in Xenopus laevis embryos. Science 253, 194-196.

Bürglin, T. R. (1994). A comprehensive classification of homeobox genes. In Guidebook to the Homeobox Genes (ed. D. Duboule), pp. 27-71. Oxford University Press, Oxford.

Chen, Z.-F. and Behringer, R. R. (1995). Twist is required in head mesenchyme for cranial neural tube morphogenesis. Genes \& Dev. 9, 686699.

Cho, K. W. Y., Blumberg, B., Steinbesser, H. and De Robertis, E. M. (1991). Molecular nature of Spemann's organizer: the role of the Xenopus homeobox gene Goosecoid. Cell 67, 1111-1120.

Ciruna, B. G., Schwartz, L., Harpal, K., Yamaguchi, T. P. and Rossant, J. (1997). Chimeric analysis of fibroblast growth factor receptor-1 (Fgfr1) function: a role for FGFR1 in morphogenetic movement through the primitive streak. Development 124, 2829-2841.

Danilov, V., Blum, M., Schweickert, A., Campione, M. and Steinbeisser, H. (1998). Negative autoregulation of the organizer-specific homeobox gene goosecoid. J. Biol. Chem. 273, 627-635

Deng, C., Bedford, M., Li, C., Xu, X., Yang, X., Dunmore, J. and Leder, P. (1997). Fibroblast growth factor receptor-1 (FGFR-1) is essential for normal neural tube and limb development. Dev. Biol. 185, 42-54.

Dymecki, S. M. (1996). Flp recombinase promotes site-specific DNA recombination in embryonic stem cells and transgenic mice. Proc. Natl. Acad. Sci. USA 93, 6191-6196.

Ferreiro, B., Artinger, M., Cho, K. and Niehrs, C. (1998). Antimorphic goosecoids. Development 125, 1347-1359.

Francis-West, P., Ladher, R., Barlow, A. and Graveson, A. (1998). Signaling interactions during facial development. Mech. Dev. 75, 3-28.

Friedrich, G. and Soriano, P. (1991). Promoter traps in embryonic stem cells: a genetic screen to identify and mutate developmental genes in mice. Genes Dev. 5, 1513-1523.
Gans, C. and Northcutt, R. G. (1983). Neural crest and the origin of vertebrates: a new head. Science 220, 268-274.

Gaunt, S. J., Blum, M. and De Robertis, E. M. (1993). Expression of the mouse Goosecoid gene during mid-embryogenesis may mark mesenchymal cell lineages in the developing head, limbs and body wall. Development 117, 769-778.

Gendron-Maguire, M., Mallo, M., Zhang, M. and Gridley, T. (1993). Hoxa2 mutant mice exhibit homeotic transformation of skeletal elements derived from cranial neural crest. Cell 75, 1317-1331.

Goriely, A., Stella, M., Coffinier, C., Kessler, D., Mailhos, C., Dessain, S. and Desplan, C. (1996). A functional homologue of Goosecoid in Drosophila. Development 122, 1641-1650.

Grüneberg, H. (1963). The pathology of development. A study of inherited skeletal disorders in animals. Blackwell Scientific Publications. Oxford, U.K. pp. 31.

Grüneberg, F. R. S. and McLaren, A. (1972). The skeletal phenotype of some mouse chimeras. Proc. R. Soc. Lond. 182, 9-23.

Grüneberg, H. and Wickramaratne, G. A. (1974). A re-examination of two skeletal mutants of the mouse, vestigial-tail $(v t)$ and congenital hydrocephalus (ch). J. Embryol. Exp. Morphol. 31, 207-222.

Hahn, M. and Jäckle, H. (1996). Drosophila Goosecoid participates in neural development but not in body axis formation. EMBO J. 15, 3077-3084.

Hall, B. K. and Miyake, T. (1992). The membranous skeleton: the role of cell condensations in vertebrate skeletogenesis. Anat. Embryol. 186, 107-124.

Hall, B. K. and Miyake, T. (1995). Divide, acculumate, differentiate: cell condensation in skeletal development revisited. Intl. J. Dev. Biol. 39, 881893.

Heanue, T. A., Johnson, R. L., Izpisua-Belmonte, J. C., Stern, C. D., De Robertis, E. M. and Tabin, C. J. (1997). Goosecoid misexpression alters the morphology and Hox gene expression of the developing chick limb bud. Mech. Dev. 69, 31-37.

Hill, R. E., Favor, J., Hogan, B. L. M., Ton, C. C. T., Saunders, G. F., Hanson, I. M., Prosser, J., Jordan, T., Hastie, N. D. and van Heyningen, V. (1991). Mouse Small eye results from mutations in a Paired-like homeobox-containing gene. Nature 354, 522-525.

Hogan, B. L. M., Beddington, R. S. P., Constantini, F. and Lacy, E. (1994). Manipulating the mouse embryo. A laboratory manual. Cold Spring Harbor Laboratory Press, Cold Spring Harbor, NY.

Izpisúa-Belmonte, J. C., De Robertis, E. M., Storey, K. G. and Stern, C. D. (1993). The homeobox gene Goosecoid and the origin of organizer cells in the early chick blastoderm. Cell 74, 645-659.

Kelly, S. J. (1977). Studies of the developmental potential of 4- and 8-cell stage mouse blastomeres. J. Exp. Zool. 200, 365-376.

Kingsley, D. M., Bland, A. E., Gruber, J. M., Russell, L. B., Copeland, N. G. and Jenkins, N. A. (1992). The mouse short ear skeletal morphogenesis locus is associated with defects in a bone morphogenetic member of the TGF beta superfamily. Cell 71, 399-410.

Kochhar, D. M. (1973). Limb development in mouse embryos. I. Analysis of teratogenic effects of retinoic acid. Teratology 7, 289-298.

Kume, T., Deng, K.-Y., Winfrey, V., Gould, D. B., Walter, M. A. and Hogan B. L. M. (1998). The Forkhead/winged helix gene Mf1 is disrupted in the pleiotropic mouse mutation congenital hydrocephalous. Cell 93, 985-996.

Larsen, W. L. (1993). Human embryology. Churchill Livingstone, New York, NY. p. 360 .

Liu, X., Wu, H., Loring, J., Hormuzdi, S., Disteche, C. M., Bornstein, P. and Jaenisch, R. (1997). Trisomy eight in ES cells is a common potential problem in gene targeting and interferes with germ line transmission. Dev. Dyn. 209, 85-91.

Mallo, M. and Gridley, T. (1996). Development of the mammalian ear: coordinate regulation of formation of the tympanic ring and the external acoustic meatus. Development 122, 173-179.

Martin, J. F., Bradley, A. and Olson, E. N. (1995). The Paired-like homeo box gene MHox is required for early events of skeletogenesis in multiple lineages. Genes \& Dev. 9, 1237-1249.

Mintz, B. (1962). Formation of genetically mosaic mouse embryos. Amer. Zool. 2, 432.

Moore, W. J. and Mintz, B. (1972). Clonal model of vertebral column and skull development derived from genetically mosaic skeletons in allophenic mice. Dev. Biol. 27, 55-70.

Niehrs, C., Keller, R., Cho, K. W. Y. and De Robertis, E. M. (1993). The homeobox gene Goosecoid controls cell migration in Xenopus embryos. Cell 72, 491-503.

Quinn, J. C., West, J. D. and Hill, R. E. (1996). Multiple functions for Pax6 in mouse eye and nasal development. Genes Dev. 10, 435-446. 
Rashbass, P., Cooke, L. A., Herrmann, B. G. and Beddington, R. S. (1991) A cell autonomous function of Brachyury in $T / T$ embryonic stem cell chimaeras. Nature 353, 348-351.

Rijli, F. M., Mark, M., Lakkaraju, S., Dierich, A., Dollé, P. and Chambon, P. (1993). A homeotic transformation is generated in the rostral branchial region of the head by disruption of Hoxa-2, which acts as a selector gene. Cell 75, 1333-1349.

Rivera-Pérez, J. A., Mallo, M., Gendron-Maguire, M., Gridley, T. and Behringer, R. R. (1995). Goosecoid is not an essential component of the mouse gastrula organizer but is required for craniofacial and rib development. Development 121, 3005-3012.

Satokata, I. and Maas, R. (1994). Msxl deficient mice exhibit cleft palate and abnormalities of craniofacial and tooth development. Nature Genet. 6, 348-355.

Schwenk, F., Baron, U. and Rajewsky, K. (1995). A cre-transgenic mouse strain for the ubiquitous deletion of loxP-flanked gene segments including deletion in germ cells. Nucleic Acids Res. 23, 5080-5081.

Schulte-Merker, S., Hammerschmidt, M., Beuchle, D., Cho, K. W. Y., De Robertis, E. M. and Nüsslein-Volhard, C. (1994). Expression of zebrafish Goosecoid and no tail gene products in wild-type and mutant no tail embryos. Development 120, 843-852.

Smith, K. K. and Schneider, R. A. (1998). Have gene knokouts caused evolutionary reversals in the mammalian first arch? Bioessays 20, 245-255.

Stachel, S. E., Grunwald, D. J. and Myers, P. (1993). Lithium perturbation and Goosecoid expression identify a dorsal specification pathway in the pregastrula zebrafish. Development 117, 1261-1274.

Tarkowski, A. K. (1961). Mouse chimaeras developed from fused eggs. Nature 190, 857-860. te Riele, H., Maandag, E. R., Clarke, A., Hooper, M. and Berns, A. (1990). Consecutive inactivation of both alleles of the pim-1 proto-oncogene by homologous recombination in embryonic stem cells. Nature 348, 649-651.

Wakamiya, M., Rivera-Pérez, J. A., Baldini, A. and Behringer, R. R. (1997). Goosecoid and Goosecoid-related genes in mouse embryogenesis. Cold Spring Harbor Symposia on Quantitaitve Biology 62, 145-149.

Weitzer, G., Milner, D. J., Kim, J. U., Bradley, A. and Capetanaki, Y. (1995). Cytoskeletal control of myogenesis: a desmin null mutation blocks the myogenic pathway during embryonic stem cell differentiation. Dev. Biol. 172, 422-439.

Wilson, V., Manson, L., Skarnes, W. C. and Beddington, R. S. (1995). The $T$ gene is necessary for normal mesodermal morphogenetic cell movements during gastrulation. Development 121, 877-886.

Wood, S. A., Allen, N. D., Rossant, J., Auerbach, A. and Nagy, A. (1993). Non-injection methods for the production of embryonic stem cell-embryo chimaeras. Nature 365, 87-89.

Yamada, G., Mansouri, A., Torres, M., Stuart, E. T., Blum, M., Schultz, M., De Robertis, E. M. and Gruss, P. (1995). Targeted mutation of the murine Goosecoid gene results in craniofacial defects and neonatal death. Development 121, 2917-2922.

Zambrowicz, B. P., Imamoto, A., Fiering, S., Herzenberg, L. A., Kerr, W. G. and Soriano, P. (1997). Disruption of overlapping transcripts in the ROSA $\beta$ geo26 gene trap strain leads to widespread expression of $\beta$ galactosidase in mouse embryos and hematopoietic cells. Proc. Natl. Acad. Sci. USA 94, 3789-3794.

Zhu, C. C., Yamada, G., Nakamura, S., Terashi, T., Schweickert, A. and Blum, M. (1998). Malformation of trachea and pelvic region in Goosecoid mutant mice. Dev. Dyn. 211, 374-381. 